\title{
Aluminum Alloy Production for the Reinforcement of the CMS Conductor
}

\author{
S. Sequeira Tavares, B. Blau, D. Campi, B. Curé, I. L. Horvath, P. Riboni, S. Sgobba, and R. P. Smith
}

\begin{abstract}
The Compact Muon Solenoid (CMS) is one of the general-purpose detectors to be provided for the Large Hadron Collider (LHC) project at CERN. The design field of the CMS superconducting magnet is $4 \mathrm{~T}$, the magnetic length is $12.5 \mathrm{~m}$ and the free bore is $6 \mathrm{~m}$. To reinforce the high-purity $(\mathbf{9 9 . 9 9 8 \% )}$ Al-stabilized conductor of the magnet against the magnetic loadings experienced during operation at $4.2 \mathrm{~K}$, two continuous sections of Al-alloy (AA) reinforcement are Electron Beam (EB) welded to it. The reinforcements have a section of $24 \times 18 \mathrm{~mm}$ and are produced in continuous $2.55 \mathrm{~km}$ lengths. The alloy EN AW-6082 has been selected for the reinforcement due to its excellent extrudability, high strength in the precipitation hardened states, high toughness and strength at cryogenic temperature and good EB weldability. Each of the continuous lengths of the reinforcement is extruded billet on billet and press quenched on-line from the extrusion temperature in an industrial extrusion plant. In order to insure the ready EB weldability of the reinforcement onto the pure aluminum of the insert, tight dimensional tolerances and proper surface finish of the reinforcement are required in the as-extruded state. As well, in order to facilitate the winding operation of the conductor, the uniformity of the mechanical properties of the extruded reinforcement, especially at the billet on billet joints, is critical. To achieve these requirements in an industrial environment, substantial effort was made to refine existing production techniques and to monitor critical extrusion parameters during production. This paper summarizes the main results obtained during the establishment of the extrusion line and of the production phase of the reinforcement.
\end{abstract}

Index Terms-Continuous extrusion, cryogenic applications, high strength aluminum alloys, materials processing.

\section{INTRODUCTION}

$\mathbf{T}$ HE $20 \mathrm{kA}$ conductor for the CMS magnet, to be produced in twenty continuous lengths of $2.55 \mathrm{~km}$, consists of a superconducting cable stabilized with high purity aluminum (referred as "insert"), reinforced with continuous sections of high strength Aluminum Alloy (AA). These are Electron Beam (EB) welded to it. The reinforcement confers the necessary strength to the conductor to withstand the stresses acting during cooling, energizing and operation. Engineering studies undertaken during the design of the CMS solenoid indicated that the coil winding design is optimally balanced mechanically and thermally by incorporating the required axial and radial

Manuscript received September 24, 2001. The work at Fermilab was supported by the U.S. Department of Energy under Contract DE-AC02-76CH03016.

S. Sequeira Tavares, D. Campi, B. Curé, and S. Sgobba are with CERN, CH-1211 Geneva 23, Switzerland (e-mail: Sandra.Sequeira.Tavares@cern.ch).

B. Blau, I. L. Horvath, and P. Riboni are with the Swiss Federal Institute of Technology, 8093 Zürich, Switzerland.

R. Smith is with Fermi National Accelerator Laboratory, Batavia, IL 60510-0500 USA.

Publisher Item Identifier S 1051-8223(02)03577-7. strength directly in the conductor rather than in a thick supporting cylinder [1]. After optimization studies and tests which focused on industrial capability of producing conductor lengths of $2.55 \mathrm{~km}$, the conductor design consisting of two continuous sections of high strength aluminum alloy EB welded to the insert, was selected [2].

To achieve uniform pre-bending of the reinforced conductor during coil winding, high uniformity of yield strength is required (within 12\%). This places critical constraints on the fabrication of the reinforcement. Development programs were established with commercial firms to produce qualification sections of the continuously extruded reinforcement. The required surface finish and dimensional tolerances, as well as the specified tensile properties could be achieved. An uniform yield strength was obtained over the full length of the sections. For the as-received state at Room Temperature (RT), tensile properties and uniformity of yield strength were specified. As well, the minimum RT tensile properties were also specified after a special heat treatment, representative of the heat cycle that the conductor experiences during the curing of the epoxy resin following the winding operation. During the pre-production phase a number of parameters found critical to the success of the process were incorporated into the quality assurance procedures of the manufacture. Testing at CERN of samples taken from the production sections has demonstrated that the specified range for the selected parameters results in extruded sections of fully adequate quality.

\section{Alloy AND TEMPER}

An extensive and comparative characterization of the low temperature properties of several AAs and of their weldability to high purity aluminum (99.998\%) resulted in the selection of the typical extrusion alloy EN AW-6082 for the reinforcement [3], [4]. The underaged and stabilized temper T51 [5] guarantees the minimum required properties (see Section V-A-1 and Table II) in the as-received state. Moreover, this temper has the advantage of achieving peak-aged properties after the curing cycle applied to the magnet [6].

\section{FABRICATION METHOD AND ITS OPTIMIZATION}

The selected production method consists of a continuous billet on billet extrusion process with an on-line quench from extrusion temperature. The die is provided with two exits, resulting in two identical sections from each extrusion campaign. This process shows two limitations when extruding long structural lengths as the reinforcement of the CMS conductor: 


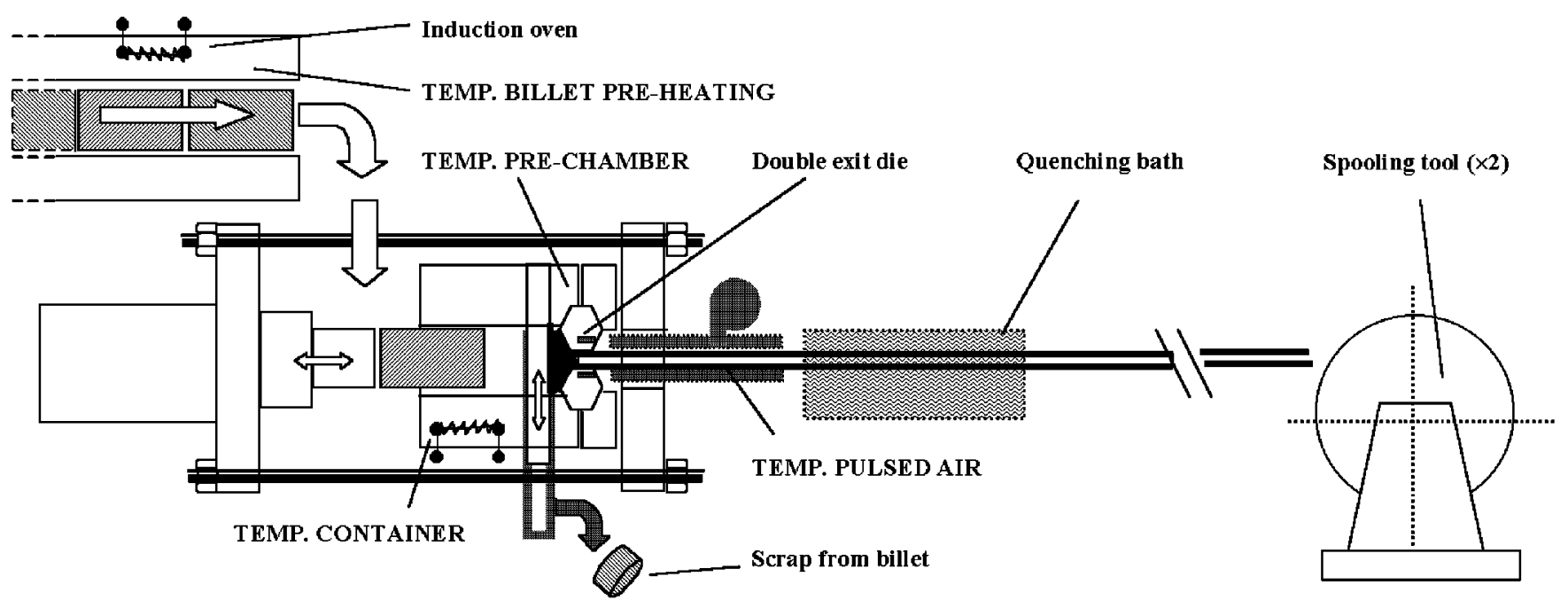

Fig. 1. Schematic representation of the improved extrusion line. The monitored temperatures are indicated in capital letters.

\section{A. Transverse Weld}

The presence of a transverse weld in long AA extruded sections is well described in the literature [7]. This defective region, generally discarded in the production of short extruded lengths, is mainly due to contaminants and oxides present at the surface of the billets. The sequential extrusion of several billets entraps the contaminants within the reinforcement, generating the defective region. In order to guarantee a sound billet/billet interface, the mating surfaces of the billets were properly conditioned.

\section{B. Improper Solution Heat Treating and Quenching}

The pause ("stop-over") of the extrusion press for the introduction of a new billet generates a region of nonisothermal extrusion, inducing a local degradation of the mechanical properties of the reinforcement. This degradation is calculated as the ratio of the difference between the maximum and the minimum value of a property over its highest value. The phenomenon arises from two different effects:

1) improper solution heat treating of the material due to cooling inside the pre-chamber of the press during the stop-over time (nominal solution heat treating temperature for this alloy is between $525^{\circ} \mathrm{C}$ and $540{ }^{\circ} \mathrm{C}$ [8]);

2) ineffective air quenching instead of water quenching of the material already extruded and waiting to enter the quench bath. The quenching rate is very important for the fine precipitation of the hardening elements in solid solution for this alloy.

Fig. 1 shows a schematic drawing of a standard extrusion line with the implemented devices in order to achieve almost isothermal extrusion conditions. The insertion of a heating device around the pre-chamber avoids the cooling of the metal that has not been extruded and allows the extrusion exit temperature to be maintained close to the nominal solution heat treating temperature. The forced air heating system at the exit of the press prevents the extruded section from cooling down to temperatures for which effective water quenching would no longer be possible. These two improvements together with an increased
TABLE I

Nominal Composition of the Alloy EN AW-6082, ACCORDING TO THE StANDARD EN 573-3 (Single VAlues RePRESENT MAXIMUM Allowed CONTENT) AND ANALYZED COMPOSITION OF THE TESTED SECTIONS (wt\%)

\begin{tabular}{ccccc}
\hline & & \multicolumn{3}{c}{ Tested sections } \\
\cline { 3 - 5 } Element & Standard & \multicolumn{2}{c}{ Pre-production phase } & $\begin{array}{c}\text { Production phase } \\
\text { EN 573-3 }\end{array}$ \\
\cline { 3 - 5 } & & $\begin{array}{c}\text { General } \\
\text { characterization }\end{array}$ & $\begin{array}{c}\text { Study of time } \\
\text { of stop-over }\end{array}$ & $\begin{array}{c}\text { ave all } \\
\text { melts used) }\end{array}$ \\
\hline $\mathrm{Si}$ & $0.7-1.3$ & 0.96 & 0,97 & 0.97 \\
$\mathrm{Fe}$ & 0.50 & 0.19 & 0,21 & 0.24 \\
$\mathrm{Cu}$ & 0.10 & 0.072 & 0,031 & 0.022 \\
$\mathrm{Mn}$ & $0.40-1.0$ & 0.83 & 0,85 & 0.86 \\
$\mathrm{Mg}$ & $0.6-1.2$ & 0.73 & 0,72 & 0.75 \\
$\mathrm{Cr}$ & 0.25 & 0.011 & 0,015 & 0.027 \\
$\mathrm{Zn}$ & 0.20 & 0.035 & 0,038 & 0.034 \\
$\mathrm{Ti}$ & 0.10 & 0.020 & 0,020 & 0.019 \\
$\mathrm{Al}$ & remaining & remaining & remaining & remaining \\
\hline
\end{tabular}

volume of metal in the pre-chamber (increasing the reduction in area) made it possible to decrease the degradation of the yield strength from $30 \%$ to approximately $10 \%$ [9].

In order to control better the extrusion process, a continuous monitoring of the key extrusion parameters was implemented. A limited variation was imposed for the temperature of pre-heating of the billet, of the container, of the pre-chamber and of the pulsed air (Fig. 1). A range of allowed variation of the stopover time, key parameter as well, could be assessed following a dedicated testing campaign (see Section V-A-2).

\section{EXPEIRMENTAL CHARACTERIZATION}

\section{A. Material}

The nominal composition of EN AW-6082 as defined in the standard EN 573-3, as well as the chemical composition of the tested material, are shown in Table I.

\section{B. Sampling}

In order to evaluate the degradation of properties around the transverse weld region, tensile specimens were removed from a representative sample of length approximately $10 \mathrm{~m}$. This sample includes the transverse weld and the neighboring 
TABLE II

Summary of the Measured (SPECIFIEd/EXPeCtEd) TENSILE Properties DURING THE PRE-PRODUCTION PHASE

\begin{tabular}{cccc}
\hline Property & $\begin{array}{c}\text { Tensile strength } \\
\text { (MPa) }\end{array}$ & $\begin{array}{c}\text { Yield strength } \\
(\mathrm{MPa})\end{array}$ & $\begin{array}{c}\text { Elongation } \\
(\%)\end{array}$ \\
\hline As-received state, RT & $295(250)$ & $171(150)$ & $20(15)$ \\
\hline $\begin{array}{c}\text { After customer's } \\
\text { heat treatment, RT }\end{array}$ & $370(280)$ & $281(175)$ & $18(15)$ \\
\hline $\begin{array}{c}\text { After customer's } \\
\text { heat treatment, } 4.2 \mathrm{~K}\end{array}$ & $684(550)$ & $428(225)$ & $16(15)$ \\
\hline
\end{tabular}

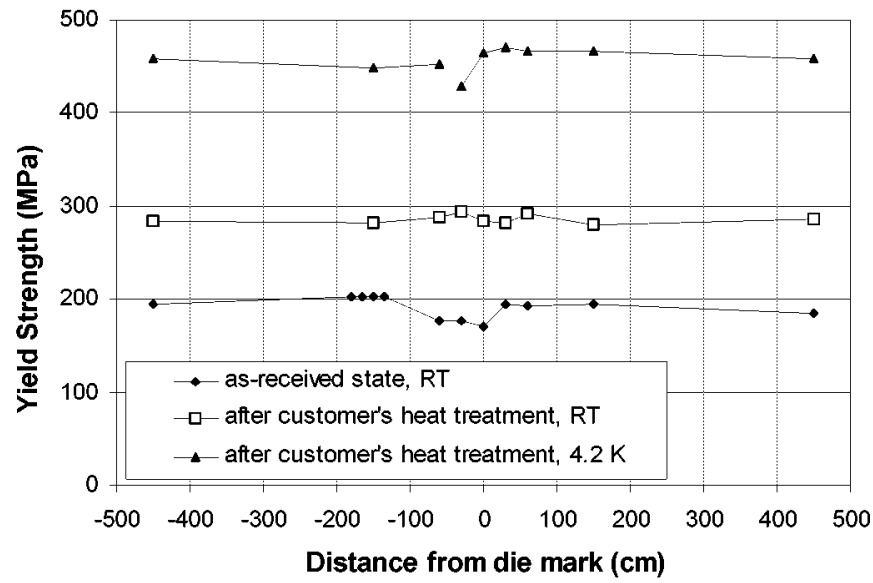

Fig. 2. Yield strength results from the pre-production phase around the die mark region.

regions of improper solution heat treating and ineffective quenching (Section III) and is centered around a "die mark." The die mark is made by the die at the moment of the stop-over of the extrusion press, when a new billet is introduced.

\section{Simulation of the Curing Cycle}

To ensure that the reinforcement will achieve peak-aged properties after curing cycle (Section II), as-received samples were subjected to a thermal treatment discussed in Section I, when required. This thermal treatment, called "customer's heat treatment," is performed by the supplier at $135^{\circ} \mathrm{C}$ during $29 \mathrm{~h}$.

\section{Non-Destructive and Destructive Testing}

The variation of the properties around the transverse weld was evaluated through electrical conductivity and tensile testing at RT. Electrical conductivity was measured by the supplier according to EN 2004-1, with a portable instrument. Tensile testing was carried out by CERN and by the supplier, according to EN 10 002-1.

\section{RESULTS}

\section{A. Pre-Production Phase}

1) General Characterization: Tensile results obtained on a pre-production section (300 $\mathrm{m}$ length), are summarized in Table II. The measured values are well above the minimum specified values, also reported for comparison. Although not specified, a minimum yield strength $\left(R_{p 0.2}\right)$ of $225 \mathrm{MPa}$ at $4.2 \mathrm{~K}$ is expected after customer's heat treatment. The
TABLE III

RESUlts OF THE EFFECT OF THE TIME OF STOP-Over ON THE TENSILE PROPERTIES OF THE REINFORCEMENT

\begin{tabular}{ccccc}
\hline \multirow{2}{*}{$\begin{array}{c}\text { Time of } \\
\text { stop-over }(\mathrm{s})\end{array}$} & \multicolumn{2}{c}{ Tensile strength } & \multicolumn{2}{c}{ Yield strength } \\
\cline { 2 - 5 } & $\begin{array}{c}\text { Minimum value } \\
\text { measured (MPa) }\end{array}$ & $\begin{array}{c}\text { Degradation } \\
(\%)\end{array}$ & $\begin{array}{c}\text { Minimum value } \\
\text { measured (MPa) }\end{array}$ & $\begin{array}{c}\text { Degradation } \\
(\%)\end{array}$ \\
\hline 36 & 284 & 10.4 & 171 & 10.5 \\
90 & 286 & 10.9 & 170 & 11.5 \\
195 & 286 & 12.0 & 170 & 11.9 \\
315 & 254 & 20.4 & 158 & 19.0 \\
\hline
\end{tabular}

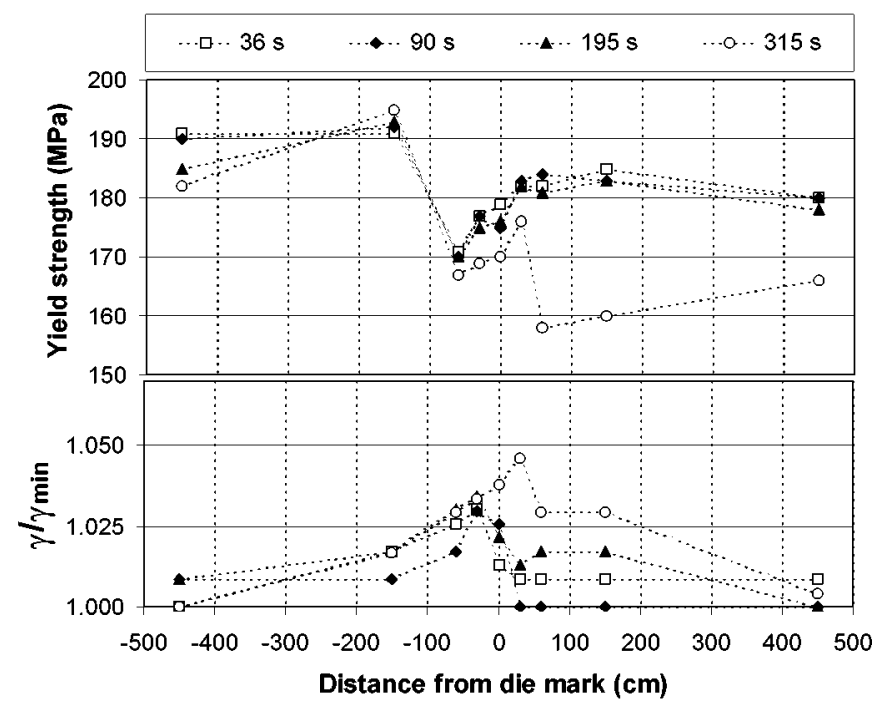

Fig. 3. Effect of the stop-over time on the yield strength. The variation of the electrical conductivity $(\gamma)$ normalized to its minimum value $\left(\gamma_{\text {min }}\right)$ is shown. Since the absolute value of $\gamma$ is influenced by the temperature of the measurement, $\gamma / \gamma_{\min }$ was plotted instead of $\gamma$ for comparison purposes.

experimental value measured after treatment is $428 \mathrm{MPa}$ at $4.2 \mathrm{~K}$, which represents a comfortable strength for the superconducting coil during operation [10].

The profiles of $R_{p 0.2}$ measured on the pre-production length, for the different tempers and testing temperatures are shown in Fig. 2.

2) Study of Stop-Over Time: A testing campaign was carried out in order to evaluate the effect of the stop-over time during billet re-supply on the tensile properties around the die mark. This campaign was aimed to assess the maximum acceptable value of stop-over time resulting in a degradation of the yield strength within the specified value (12\%). Several billets of the same melt were extruded continuously by waiting increasing stop-over times. Table III reports the measured values of tensile strength $\left(R_{m}\right)$ and $R_{p 0.2}$, as well as the degradation of $R_{p 0.2}$, for the relevant stop-over times. The profile of $R_{p 0.2}$ is shown in Fig. 3, for the same stop-over times of Table III, together with the profile of electrical conductivity $(\gamma)$.

A good correlation is found between $\gamma$ (arising from a nondestructive measurement) and $R_{p 0.2}$. For the stop-over times under $195 \mathrm{~s}$ the profiles of $R_{p 0.2}$ look very similar. Moreover, the degradation is below $12 \%$ for all cases. The profile for the stop-over time of $315 \mathrm{~s}$ shows a minimum $R_{p 0.2}$ value very close to the minimum specified (158 MPa and $150 \mathrm{MPa}$, respectively). As well, degradation (19.0\%) is higher than the maximum specified. From these results, the stop-over time was limited to 3 minutes during the production phase of the reinforcement. 


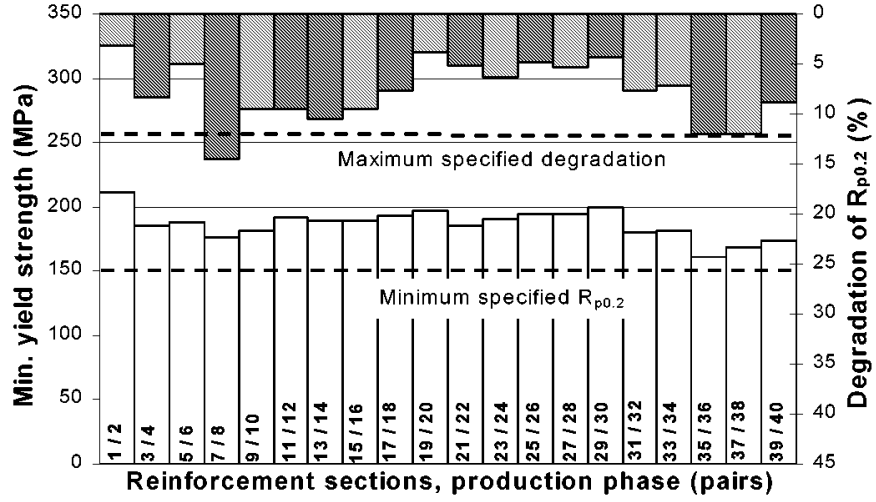

Fig. 4. Histogram showing the minimum yield strength and corresponding degradation for each reinforcement pairs of the production phase.

\section{B. Production Phase}

The lowest value measured for $R_{p 0.2}$ was $161 \mathrm{MPa}$, associated to a degradation of $12.0 \%$ (see Fig. 4). Only for one pair of coils a degradation higher than the specified value (14.6\%) was measured. Nevertheless, this pair of coils was accepted for the fabrication of a prototype conductor for winding test purposes. Specified $R_{m}$ and elongation were always respected.

During the production phase, the dimensions of the cross-section of the reinforcement, measured at least every $500 \mathrm{~m}$, were always inside the specified tolerances $( \pm 0.2 \mathrm{~mm})$. As well, parallelism and perpendicularity requirements were also fulfilled and the surface quality was within the requirements imposed to guarantee ready EB weldability.

\section{DISCUSSION AND CONCLUSIONS}

Key extrusion temperatures have been identified and a range of allowed values was established, allowing reinforcement of suitable strength, geometry and surface state to be produced. On the other hand, the control of the same parameters and in partic- ular of the time of stop-over resulted in uniform values of yield strength, a crucial parameter for the further winding of the reinforced conductor. A systematic verification of the tensile properties for different representative tempers and test temperatures (down to $4.2 \mathrm{~K}$ ) shows that the strength of the reinforcement should be largely sufficient to confer the necessary mechanical properties to the welded conductor.

\section{ACKNOWLEDGMENT}

The authors would like to thank the extrusion development and production teams of the Alcan Aluminum Valais Ltd., previously named Alusuisse Aluminum Swiss Ltd., Sierre.

\section{REFERENCES}

[1] D. Campi, A. Desirelli, J. P. Grillet, and A. Hervé, "The CMS magnet project technical design report,", CERN/LHCC 97-10, pp. 79-92, 1997.

[2] I. L. Horvath, F. Wittgenstein, F. Bertinelli, A. Desirelli, S. Sgobba, T. Tardy, D. Fritz, and J. Neueschwander, "Manufacture of Al stabilized and reinforced superconductors by electron beam welding technique," in Proc. 15th Int. Conf. Magnet Technology, vol. 2, 1997, pp. 1170-1173.

[3] F. Bertinelli, G. Favre, S. Sgobba, and T. Tardy, "Electron beam welding of the CMS superconducting cable," in Proc. 6th Int. Conf. on Welding and Melting by Electron and Laser Beams, vol. 2, 1998, pp. 805-812.

[4] R. Naoux, "Selection and welding properties of an electron beam welded aluminum alloy for the reinforcement of the conductor of the CMS magnet," CERN EST-SM-MB Internal Report, 1998.

[5] "Aluminum and aluminum alloys-Wrought products-Temper designations," British Standards Institution, BS EN 515, 1993.

[6] S. S. Tavares, A. Calvo, A. Desirelli, S. Sgobba, and I. L. Horvath, "Mechanical characterization and assessment of the CMS conductor," IEEE Trans. Appl. Superconduct., vol. 10, pp. 399-402, March 2000.

[7] T. Sheppard, Extrusion of Aluminum Alloys. Dordrecht: Kluwer Academic Publishers, 1996, pp. 311-313.

[8] Aluminum-Taschenbuch, 14th ed: Aluminum Verlag Düsseldorf, 1983.

[9] S. S. Tavares and S. Sgobba, "An improved billet on billet extrusion process of continuous aluminum alloy shapes for cryogenic applications in the CMS experiment," in Proc. Int. Conf. Advanced Materials and Processing Technologies, vol. 1, 2001, pp. 149-156.

[10] A. Desirelli, P. Fabbricatore, S. Farinon, B. Levesy, C. Ps, J. M. Rey, and S. Sgobba, "FE stress analysis of the CMS magnet coil," IEEE Trans. Appl. Superconduct., vol. 10, pp. 419-423, March 2000. 